\title{
An Exploratory Assessment of Agricultural Crimes in Georgia
}

R. Neal McIntyre, Jr., DPA

Rudy K. Prine, Ph.D.

Fred Knowles, Ph.D.

Department of Sociology, Anthropology, and Criminal Justice

Valdosta State University

Valdosta, Georgia 31698

Corresponding author: R. Neal McIntyre, Jr.: rnmcinty@valdosta.edu, (229) 249-2749

\begin{abstract}
Rural crimes have often been ignored in criminological studies. An even lesser explored subject of inquiry is the nature and prevalence of agricultural or farm crimes within rural America. The examination of these type offenses is important to having a more accurate understanding of crime. The current study adds to our current knowledge of crime by exploring instances of agricultural crime in the State of Georgia. Using a victimization survey to gather data from individuals involved in the agricultural industry, the study provides an exploratory assessment of the prevalence of farm crimes in Georgia as well as examining factors, such as years of farming experience and farm size, that were found to have a significant correlation to victimization. Based on the data, instances of trespass, poaching, and theft were more prevalent on larger farming operations. Additionally, findings suggest that individuals who had over 25 years of farming experience had more frequently been the victim of theft and poaching within the 12 month period prior to the project. Consistent with prior studies, respondents frequently elected to not report their victimization to law enforcement authorities. Future studies should examine reasons why agricultural crime frequently goes unreported to the police officials as well as exploring measures used by the farming community to reduce their probability of victimization.
\end{abstract}

Keywords: Rural crime, farm crime, agricultural crime 


\section{Introduction}

Most criminological research tends to focus on the prevalence of crime within urban settings (Donnermeyer and DeKeseredy 2014). As a result, crimes committed in rural settings have frequently been overlooked by researchers and the media despite evidence suggesting high rates of certain offenses within these areas (Donnermeyer and DeKeseredy 2014; DeKeseredy, Muzzatti, and Donnermeyer 2013; Jobes, Barclay, and Donnermeyer 2004). Although approximately 72 percent of the U.S. land area is classified by the United States Department of Agriculture (Cromartie 2013) as being rural with 46.2 million individuals living in these areas, rural crime is ranked as one of the least studied social problems in criminology (DeKeseredy, Donnermeyer, Schwartz, Tunnell, and Hall 2007).

Rural crime primarily refers to criminal acts that transpire within areas classified as being rural. These acts are generally the same acts (i.e., burglary, robbery, assault, etc.) that are frequently perpetrated in urban and suburban environments. Within rural crime, there are several different subsets of acts that are fundamentally different from commonly recognized criminal acts. One particular subset is agricultural crime. Agricultural crime involves offenses that either target agricultural property or are committed on agricultural property (Dunkelberger, Clayton, Myrick, and Lyles 1992). While normally involving a wide spectrum of offenses, some of the more prevalent acts include agricultural theft, vandalism, illegal hunting/poaching, illegal dumping of trash/refuse, and trespassing. While often being overlooked or underestimated in terms of the resulting harm, agricultural crime can have a significant impact on the economic stability of agricultural operations as well as local and state economies (Swanson and Territo 1980).

Although the commission of criminal acts is generally less frequent in rural areas, research has shown that these environments are not immune to many of the same crime problems facing more populous areas (Donnermeyer, Barclay, and Mears 2011; Donnermeyer and Tunnell 2007: Grant 2008, 2012; Tunnell 2004; Weisheit 2008; Barclay and Donnermeyer 2011). In fact, certain offenses have been found to be more prevalent in specific rural jurisdictions. Yet our understanding of crime in rural and agricultural settings is very limited (Donnermeyer and DeKeseredy 2014). Due to the impact that agriculture has on the well-being of American society combined with the extent of land space designated as "rural", there is an important need for increased research on crime in these areas. The current study seeks to help fill the gap in the sparse research pertaining to agricultural or farm crime and to provide exploratory data from the State of Georgia.

Located in the southeast corner of the United States (see Figure 1), the State of Georgia is the 8th largest state in the U.S. according to the U.S. Census Bureau (2014) with an approximate population of 10.1 million. According to the University of Georgia's Georgia Statistics System 
(http://georgiastats.uga.edu/), 24.9 percent of the state's population was listed as living in rural areas in 2010. From a land use perspective, 91.7 percent of the state's land was classified as "rural" with 26 percent of the total land area being designated as farmland. The U.S. Department of Agriculture Economic Research Service (http://www.ers.usda.gov/topics/farm-economy/farmstructure-and-organization.aspx) has noticed that the national agricultural production has been shifting away from small farms and to larger farming operations. This trend has also shown to be true in Georgia as the University of Georgia's Georgia Statistics System reported a 12 percent reduction in the number of farms from 2007 to 2012. More specifically, 103 counties (65\% of Georgia' counties) had a decrease in the number of farms during this period. While there has been a reduction in the number of farms, the average size of farms during these years experienced a modest increase of approximately 8 percent (212 acres in 2007 to 228 acres in 2012) resulting in slightly larger farming operations. Due to the vast areas of land classified as rural and used for agricultural purposes, Georgia provides an ideal setting to help broaden our understanding of farm crime.

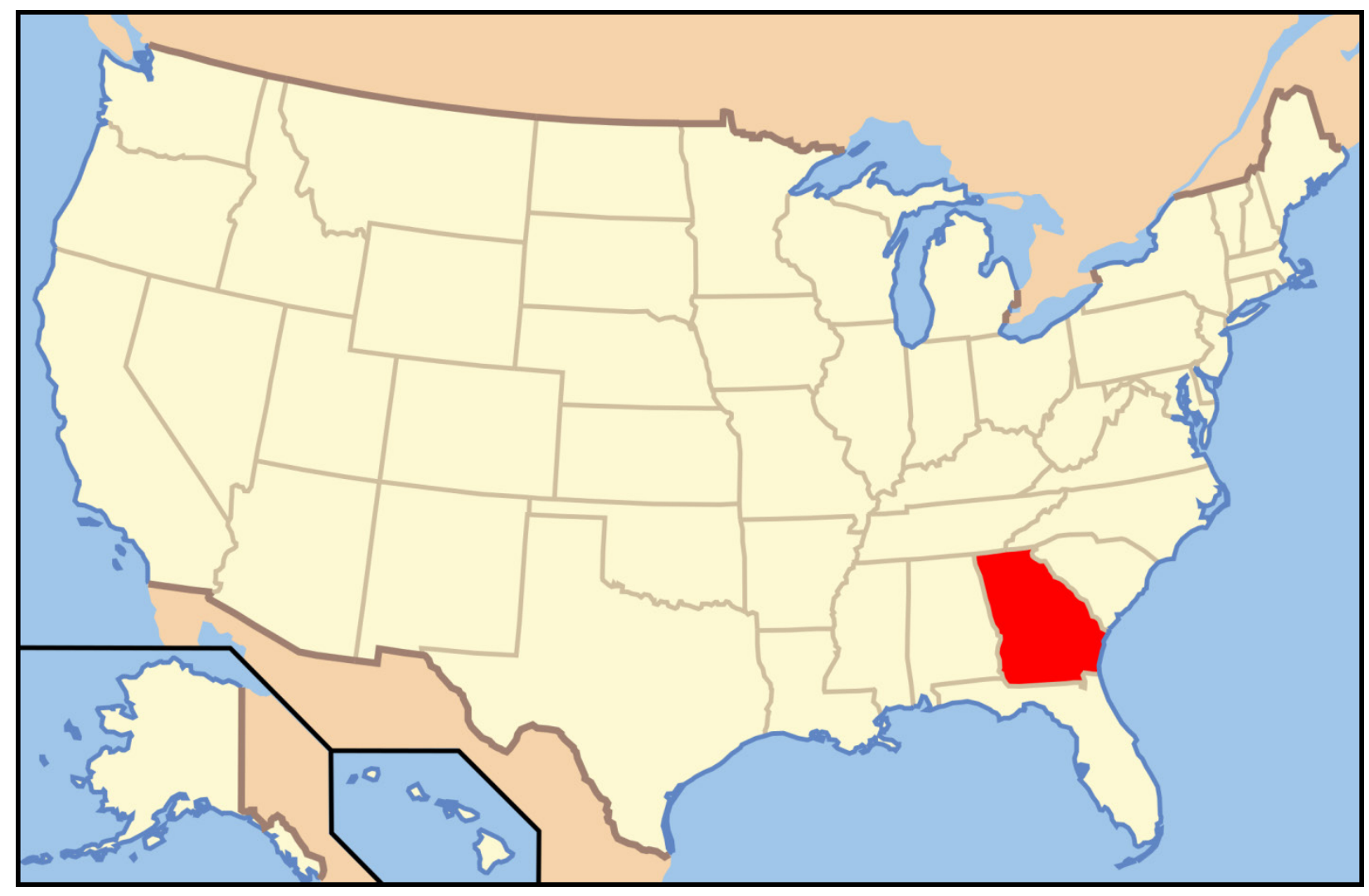

Figure 1: Location of the State of Georgia, USA 


\section{The Agricultural Industry and Crime}

Although common in usage, the conceptual construction of "rural" is difficult to define in simple terms. Weisheit and Donnermeyer (2000) identified how rural has frequently been used to describe geographical areas (such as unincorporated areas, towns, counties, etc.), specific cultures or worldviews, and bases of local economies (i.e., agriculture, mining, other extractive industries, etc.). This broad use of the term is not restrictive to descriptions but is also common among research as most studies of rural crime fail to provide an operational definition of rural (Weisheit, Falcone, and Wells 1999). Even the definition provided by the U.S. Census Bureau (2010) is ambiguous as it only specifies that rural includes all populations, housing, and territories that are not included within their definition of urban.

Rural areas often conjure up images of slow-paced environments where homogenous groups of individuals are able to live in peace and harmony while knowing their neighbors and where crime is virtually nonexistent. This stereotypical perception is often misleading and blatantly incorrect as rural areas are just as prone to criminal activity and are even more susceptible to certain crimes than urban areas (Donnermeyer and DeKeseredy 2014; Weisheit and Donnermeyer 2000). The fact that rural crime has frequently been ignored by criminological inquiry, our understanding of the nature and cause of these acts within this setting is very limited (Donnermeyer and DeKeseredy 2014).

One particular subset of rural crime that has been the subject of very few, rare studies are agricultural or farm crimes. What differentiates agricultural crime from other rural crimes and urban crime is that agricultural crime is crime that occurs on or to farm property (Dunkelberger et al. 1992). For many rural areas, agricultural crime is a major problem as many of these local economies are directly dependent on agricultural production.

From colonial times until today, agriculture has had a tremendous impact on the economic stability and wellbeing of the United States. In 2013, the United States Department of Agriculture Economic Research Service reported that agriculture and agriculture-related industries contributed $\$ 789$ billion to the U.S. gross domestic product (GDP), representing a 4.7 percent share of the entire GDP. Of this amount, $\$ 166.9$ billion (about 1\% of the GDP) was derived specifically from America's farms. When factoring in the impact that agriculture has on other related sectors, such as forestry, fishing, food, beverages, textiles, and apparel, the overall impact to the GDP is larger than this.

For local and state economies, agriculture often has an even greater impact. In 2012, the U.S. Department of Agriculture National Agricultural Statistics Service ranked the State of Georgia $15^{\text {th }}$ in terms of total value of agricultural products sold. More specifically, Georgia ranked either $1^{\text {st }}$ or $2^{\text {nd }}$ in several agricultural categories in 2012, such as the production of cotton 
and cottonseed, hay, poultry and eggs, and peanuts (U.S. Department of Agriculture National Agricultural Statistics Service 2012). These rankings reinforce the description of agriculture as being the main driver of the state's economic engine as it contributes $\$ 72.5$ billion annually to the $\$ 786.5$ billion economy (University of Georgia Extension Service n.d.). The agriculture industry is also Georgia's primary source of employment with one in seven people throughout the state being employed in agriculture, forestry, or a related field (Georgia Department of Agriculture, January 2012). While it is clear that agriculture has a significant impact on Georgia's economy, it's correlation to the financial stability and wellbeing of those employed in this sector is even more dramatic.

Successful agricultural production is dependent on several necessary factors, some of which are within the control of the producer (such as the proper application of seed, fertilizer, etc.) while others are beyond their control, such as proper weather conditions and rainfall. The perpetration of crime on farmland is one of the many factors outside of the control of the producer that has a detrimental impact on the overall profitability and productiveness of agricultural operations. Although there are agencies and organizations that track historical weather patterns and trends, and make recommendations for the proper application and use of seeds, fertilizers, and other chemicals, no entity measures the amount of crime that transpires on and to farm operations (Weisheit and Donnermeyer 2000). The two primary sources of crime data is derived from the Federal Bureau of Investigation's (FBI's) Uniform Crime Reports (UCR) and the National Crime Victimization Survey (NCVS), although neither provides a classification for farm or agricultural crime. Additionally, the UCR is only comprised of criminal acts reported to the police, which lead to many questions regarding the nature and extent of unreported crime. This is especially important when considering that many agricultural crimes go unreported to authority figures (Weisheit and Donnermeyer 2000; Barclay, Donnermeyer, Doyle, and Talary 2001; Mears, Scott, and Bhati 2007). Even if a NCVS instrument reached a farmer there are no agricultural related questions on the survey.

In general, rural areas experience less crime than urban areas (Dunkelberger et al. 1992; Weisheit and Donnermeyer 2000; Donnermeyer and DeKeseredy 2014) and there is speculation that these lower rates of crime reflect greater informal controls in rural areas (Weisheit et al, 1999). Regardless, crime is not absent from rural and agricultural areas. In fact, the limited research conducted on farm crime indicates that some specific criminal acts have a higher rate of occurrence in agricultural areas (Jobes et al. 2004; DeKeseredy et al. 2013). Donnermeyer and DeKeseredy (2014) noted how women living in the rural U.S. are at a much greater risk of being the victim of intimate partner violence (IPV) but this isn't the only act that has an increased probability in rural areas. Farm operations have been found to suffer from higher rates of burglary than do metropolitan businesses (Donnermeyer et al. 2011). While the manufacturing, distribution, and use of illegal substances is certainly an urban problem, rural and agricultural areas are not immune to these substances (Tunnell 2004; Donnermeyer and Tunnell 2007; Grant, 
2008, 2012; Weisheit 2008). Critical issues for law enforcement in rural areas include the production, distribution of methamphetamine and the cultivation and distribution of marijuana.

In focusing on agricultural crimes specifically, vandalism and theft seem to be endemic to the U.S. heartland (Barclay and Donnermeyer 2011). Most farm crimes are property-related which a wide range of acts from theft of livestock, machinery, tools, and farm produce to the destruction of property (Barclay 2001; Anderson and McCall 2005; Donnermeyer and Barclay 2005; Mears et al. 2007; Jones 2008). In surveying Iowa farmers, Swanson and Territo (1980) found that 80 percent had been victims of theft over the prior 3-year period. Swanson and Territo (1980) noted the following points (the amounts are even more remarkable when considering inflation since these dollar values were established):

- Theft of avocado, lime, and mango fruit in Florida accounts for a loss of \$1 million annually

- Timber theft in western Washington accounts for \$1 million in annual losses

- Pesticide theft accounts for $\$ 2$ million in annual losses

- California farmers collectively experience $\$ 30$ million a year in losses to theft

- Livestock theft accounts for \$20 million in annual losses of with only about 17 percent recovered.

Further studies have found that in examining farm size, larger farms tend to be victimized more frequently (McCall 2003; Mears et al. 2007). Larger farms also provide instances of increased isolation that provides more opportunities for victimization due to the lack of guardianship (Bunei, Rono, and Chessa 2013). This isolation combined with easy access to public roads presents problems to farmers as many of their possessions are portable and are relatively easy and quick to steal (Barclay et al. 2001). In comparison to other businesses, farmers generally use fewer security measures and are more reluctant to report crimes (Jones, 2008). While the data indicates the impact of these offenses and although farm crimes have been found to be widespread and costly to farmers (Barclay 2001), only limited studies have focused on this topic. This echoes the need for more studies to utilize rural areas as natural laboratories for more research (Weisheit and Donnermeyer 2000) on rural, and more specifically agricultural, crime.

\section{Methodology}

To collect data for this project, an electronic victimization survey was prepared in SurveyMonkey, an online survey platform used to collect responses from a wide spectrum of individuals through an electronic link distributed via email. The survey inquired about five specific crimes committed on or against agricultural property (i.e., theft, vandalism, illegal dumping of trash/refuse, trespassing, and illegal hunting/poaching) within the past 12 months. 
Additional inquiries were made regarding the demographic data of the respondents (i.e., age, race, gender, income, etc.) as well as their farming or ranching operation (i.e., how many acres were used in farming or ranching, what crops were grown, what type of livestock were raised, etc.).

In order to reach the target individuals, those involved with agriculture in the capacity of farming and ranching, within the State of Georgia, assistance was sought from Georgia Farm Bureau. As the largest and strongest voluntary agricultural organization in the state, the Georgia Farm Bureau serves more than 300,000 member families. According to the Georgia Farm Bureau (http://www.gfb.org/aboutus/default.html), its purpose is to, "provide leadership and assistance to the agricultural sector, promote farm products, aid in agri-related procurement, to act as a spokesperson for farmers in the legislative arena, to be an industry leader in the development and expansion of farm markets, and to seek increased agricultural research opportunities and educational funding". Thus their membership consists mainly of farm families in rural communities and of people and businesses associated with agriculture in Georgia.

Georgia Farm Bureau has email addresses on approximately 10,000 members who have identified themselves as being involved in the agricultural industry through farming and/or ranching. The current researchers had indirect access to this distribution list, however, for proprietary reasons the Georgia Farm Bureau did not release personal data about their customers. Thus, the Georgia Farm Bureau sent the electronic survey link to those farm operators. The email included a brief description outlining the nature and purpose of the survey along with the statement that participation was voluntary. To ensure anonymity, participant contact information (such as email addresses) was not disclosed to the researchers. While demographic information, such as race, gender, county of residence, etc., were collected, no specific identifiable information (e.g., names, addresses, phone numbers, social security numbers, etc.) was collected in this project. With the survey link being distributed to the membership by Georgia Farm Bureau, there was no direct communication between the researchers and the participants. This methodology protected the privacy of the respondents and ensured their anonymity from the researchers.

To help increase the response rate, Georgia Farm Bureau was willing to send two subsequent reminders to the participants following the original email. The membership received the first e-mail request in February, 2015 with two follow-up emails sent in April 2015 and July 2015. All responses for this project were collected and stored in the SurveyMonkey ${ }^{\circledR}$ program until the response collection time was finished (late August 2015). The researchers used SPSS, one of the most popular statistical programs in the social sciences for the analysis.

The project will provide demographic data on the respondents (i.e., race, gender, age, etc.) along with characteristics of their farming and/or ranching operation (i.e., number of acres, crops 
grown, livestock raised, etc.). Chi-square analysis determined the significance, if any, between the dependent variables (size of farm and years farming) and the independent variable (i.e., reported victimization of select offenses within the past 12 months). The analysis of farm size to reported victimization allows a comparison between the current study and past farm crime studies conducted by Barlcay (2001). To the best of our knowledge, this study will be the first to provide an exploratory examination of victimization in relation to years of farming experience.

\section{Results}

Of the estimated 10,000 Georgia Farm Bureau members who received the surveys, 415 were completed and submitted. This represents a return rate of 4.15 percent. While well below the ideal return rate of 20 percent within most criminological research that uses web-based surveys, the Georgia Farm Bureau reports their normal return rate for electronic membership survey to be within the range of $4-5$ percent. On a more positive note, the participants of this project represented, by location of habitation, 113 of 159 Georgia counties this equates to 71 percent of the total counties in Georgia. A spatial analysis of a Georgia map, with all counties marked as either represented or not revealed no major discrepancies in coverage. In other words, the study represented all geographic regions of the state.

Table 1 outlines selective demographic data related to the respondents. The respondents had an average age of 59, which is in conformity with national averages and is indicative of the average farmer categorized as an older individual. According to the U.S. Department of Agriculture's 2012, Census of Agriculture the national average for farm operators was 58 years old. The 2012 Census of Agriculture reported the average age of Georgia farmers to be 59 years old. Respondents reported an overall average gross income from farming operations of $\$ 232,177$ with an income range of $\$ 25$ million - \$1 per year. While slightly higher, the average gross farming income for the current study is comparable to the average per farm market value of products sold $(\$ 219,020)$ as outlined in the 2012 Census of Agriculture for Georgia.

The survey participants were mostly white and male. In fact, roughly 74 percent of the respondents identified themselves as being male with the remaining 26 percent self-identified as being female. This finding was similar to the 2012 Census of Agriculture for Georgia reporting that 85 percent of the farming population was male and 15 percent were female. The participants were overwhelmingly (96.5\%) white which closely resembles the 94 percent of white farmers reported by the 2012 Census. Additionally, almost half (49.6\%) of the survey participants can best be described as being very experienced with farming/ranching, having been active in the 
Table 1: Respondent Demographics

\section{Characteristics}

Gender

Male

Female

Race

White

African American

Hispanic

Native American

Other

Is Farming Your Sole Occupation

Yes

No

Years Farming

$<10$ Years

$11-24$ Years

$25+$ Years

Unknown

Cropland Ownership

Majority of land is owned

Majority of land is rented

Equally rented and owned

Do not have row crops

Livestock Land Ownership

Majority of land is owned

Majority of land is rented

Equally rented and owned

Do not raise livestock

\section{Percentage}

73.9

26.1

95.5

0.3

0.3

0.9

2.0

29.3

70.7

10.6

19.3

49.6

20.5

35.6

8.7

8.0

47.8

56.8

6.6

6.3

30.3
Characteristics

Age

Gross Income

Cropland Acres

Livestock Acres

$\begin{array}{cc}\text { Range } & \text { Average } \\ 21-89 & 59 \\ \$ 1-\$ 25 \text { mill } & \$ 232,177 \\ 1-9000 & 332 \\ 1-2000 & 121\end{array}$


lifestyle for 25 years or more. This was followed by 19.3 percent who indicated that they had been involved in farming/ranching for $11-24$ years and 10.6 percent having been in the occupation for 10 years or less. While more of the respondents have been involved in farming and ranching for many years, approximately 71 percent stated that farming/ranching was not their sole occupation. This figure was significantly higher than the 53 percent of Georgia farmers included in the 2012 Census of Agriculture that indicated that farming was not their primary occupation.

Of those who indicated that they either farm row crops or raise livestock, more individuals (approximately 36\% and 57\% respectively) indicated that they own the land used for their agricultural purposes (see Table 1). Land used for growing crops ranged from a low of 1 acre to a high of 9,000 acres (332 average acres). The average acreage used for livestock was 121 acres with a range of $1-2,000$ acres. According to the 2012 Census of Agriculture, the average farm size in Georgia was 228 acres, which to the best of the researcher's knowledge, includes both, cropland and land used for raising livestock.

The most common crop grown was corn, approximately 19 percent, followed by peanuts at 15 percent (see Table 2). Many (42\%) respondents also selected "Other" as their option for crops grown. These individuals then self-identified that they grew pumpkins, fruit trees, hay, etc., The most common livestock raised was cattle (51\%) followed by approximately 16 percent indicating that they raised chickens.

Drawing from an earlier study of farm crime conducted by Dunkelberger et al. (1992), farm classification reflected a combination of acreage and income into three categories: small farm, medium farm, and large farm. Using a variation of this, the current study defines a small farm as being less than 50 acres; a medium farm being 50 - 150 acres; and a large farm being more than 150 acres. This range of acreage in defining farms is identical to the acreage parameter established by Dunkelberger et al. (1992).

A chi-square analysis of farm size and victimization in Table 3 indicates that theft, trespassing, and poaching were significant at 0.01 . While vandalism and illegal dumping of refuse were not found to be statistically significant, it should be noted that larger farms experienced higher rates of victimization in this offenses as well. The finding that larger farms had higher rates of victimization was consistent with results of similar studies examining burglary, theft, and malicious damage against U.S. farms (Dunkelberger et al., 1992; Farmer and 


\section{Table 2: Products of Agricultural Enterprises}

\begin{tabular}{|c|c|c|c|c|c|}
\hline \multirow[t]{2}{*}{ Farm Characteristics } & \multicolumn{5}{|c|}{ Size of farms } \\
\hline & All & Small & Medium & Large & Missing \\
\hline \multicolumn{6}{|l|}{ Crop Enterprise } \\
\hline Peanuts............... & $14.5 \%$ & $1.7 \%$ & $1.9 \%$ & $10.6 \%$ & $0.2 \%$ \\
\hline Soybeans............. & $11.6 \%$ & $1.0 \%$ & $1.0 \%$ & $9.4 \%$ & $0.2 \%$ \\
\hline Onions................ & $2.7 \%$ & $1.2 \%$ & $0.2 \%$ & $1.2 \%$ & $0.0 \%$ \\
\hline Cucumbers........... & $7.2 \%$ & $4.3 \%$ & $1.0 \%$ & $1.7 \%$ & $0.2 \%$ \\
\hline Beans $\ldots . . . \ldots \ldots \ldots$ & $5.3 \%$ & $3.1 \%$ & $0.5 \%$ & $1.4 \%$ & $0.2 \%$ \\
\hline Grapes................ & $2.9 \%$ & $1.7 \%$ & $0.5 \%$ & $0.7 \%$ & $0.0 \%$ \\
\hline Peaches.............. & $2.4 \%$ & $1.4 \%$ & $0.2 \%$ & $0.5 \%$ & $0.2 \%$ \\
\hline Corn.................. & $.18 .6 \%$ & $4.3 \%$ & $2.9 \%$ & $11.3 \%$ & $0.0 \%$ \\
\hline Tobacco.............. & $1.0 \%$ & $0.0 \%$ & $0.2 \%$ & $0.7 \%$ & $0.0 \%$ \\
\hline Wheat $\ldots . . . \ldots \ldots \ldots$ &. $.8 .2 \%$ & $0.5 \%$ & $0.7 \%$ & $6.7 \%$ & $0.2 \%$ \\
\hline Peppers............... & $4.6 \%$ & $2.7 \%$ & $0.5 \%$ & $1.2 \%$ & $0.2 \%$ \\
\hline Sorghum............. & $3.1 \%$ & $0.0 \%$ & $0.5 \%$ & $2.4 \%$ & $0.2 \%$ \\
\hline Rye.................. & $6.0 \%$ & $1.0 \%$ & $0.5 \%$ & $4.6 \%$ & $0.0 \%$ \\
\hline Blueberries.......... & $6.3 \%$ & $3.9 \%$ & $0.5 \%$ & $1.9 \%$ & $0.0 \%$ \\
\hline Cotton .............. & $.13 .5 \%$ & $1.4 \%$ & $1.9 \%$ & $9.9 \%$ & $0.2 \%$ \\
\hline Pecans................ & - $9.9 \%$ & $1.4 \%$ & $2.9 \%$ & $5.5 \%$ & $0.0 \%$ \\
\hline Melons................ & $5.6 \%$ & $3.1 \%$ & $1.2 \%$ & $1.0 \%$ & $0.2 \%$ \\
\hline Cabbage.............. & $2.4 \%$ & $1.4 \%$ & $0.5 \%$ & $0.5 \%$ & $0.0 \%$ \\
\hline Squash................ & $8.9 \%$ & $5.3 \%$ & $1.2 \%$ & $2.2 \%$ & $0.2 \%$ \\
\hline Oats................. & . $4.3 \%$ & $1.0 \%$ & $0.0 \%$ & $3.4 \%$ & $0.0 \%$ \\
\hline Other................. & $.41 .9 \%$ & $8.0 \%$ & $10.6 \%$ & $21.4 \%$ & $1.9 \%$ \\
\hline \multicolumn{6}{|l|}{ Livestock Enterprise } \\
\hline Cattle................. & $.50 .6 \%$ & $3.1 \%$ & $12.5 \%$ & $34.7 \%$ & $0.2 \%$ \\
\hline Chickens............. & $.16 .1 \%$ & $6.5 \%$ & $3.1 \%$ & $6.5 \%$ & $0.0 \%$ \\
\hline Horses................ & $.14 .2 \%$ & $4.1 \%$ & $4.1 \%$ & $6.0 \%$ & $0.0 \%$ \\
\hline Donkeys.............. & $.5 .5 \%$ & $0.5 \%$ & $1.7 \%$ & $3.4 \%$ & $0.0 \%$ \\
\hline Goats................ & $8.7 \%$ & $3.9 \%$ & $2.2 \%$ & $2.7 \%$ & $0.0 \%$ \\
\hline Sheep................ & $\cdot 1.7 \%$ & $0.0 \%$ & $0.5 \%$ & $1.2 \%$ & $0.0 \%$ \\
\hline Other................. &. $.6 .6 \%$ & $2.4 \%$ & $1.0 \%$ & $2.2 \%$ & $1.0 \%$ \\
\hline
\end{tabular}


Voth 1989; Peale 1990; Deeds et al. 1992; Donnermeyer 1987; Cleland 1990) and those examining the prevalence of theft, trespassing, and poaching on American farming operations (McCall 2003; Mears et al. 2007).

As indicated in both Tables 3 and 4, 44 percent of the respondents said that they had been the victim of trespass regardless of farm size or years of experience. The second most common offense was theft (33.4\%) followed by illegal dumping of refuse (30.1\%), poaching (27.5\%), and vandalism (16.3\%). Results from a similar study conducted by Dunkelberger et al. (1992) indicated that 46.8 percent of Alabama farmers had experienced theft within a 12-month period while 42.7 percent were the victims of vandalism. In examining the rate of victimization amongst the three farm size groups in Table 3, large farms were victimized at a rate approximately double that of small and medium farms combined regardless of the criminal offense.

Table 3: Agricultural Victimization within the past 12 Months

\begin{tabular}{lcccccc}
\hline Crime Type & All & Small & $\begin{array}{c}\text { Size of Farms } \\
\text { Medium }\end{array}$ & Large & Missing & $\begin{array}{c}\text { Chi- } \\
\text { Square }\end{array}$ \\
\hline Theft & $33.4 \%$ & $3.0 \%$ & $8.7 \%$ & $20.5 \%$ & $1.2 \%$ & $17.622^{*}$ \\
Vandalism & $16.3 \%$ & $2.5 \%$ & $3.8 \%$ & $9.4 \%$ & $0.5 \%$ & 2.093 \\
$\begin{array}{l}\text { Illegal dumping } \\
\text { of refuse }\end{array}$ & & & & & & \\
Trespass & $30.1 \%$ & $4.7 \%$ & $7.3 \%$ & $17.5 \%$ & $0.5 \%$ & 6.323 \\
Poaching & $4.0 \%$ & $6.9 \%$ & $10.7 \%$ & $25.6 \%$ & $0.8 \%$ & $11.622^{*}$ \\
\hline
\end{tabular}

*Chi-square statistic is significant at .01

Table 4 shows the correlation of victimization to years of farming experience. Farming experience was broken into three separate categories: less than 10 years' experience, $10-24$ years' experience, and 25 years of experience or more. Theft and poaching were found to be significant at 0.05 . These findings also indicate that the more years of farming experience an individual has, the more likely the individual will be a victim of theft or poaching. While it is true that the longer one lives the more likely they are to experience any type of stressful event, the question asked whether the participants had been a victim of these offenses within the past 12 months instead of whether they had ever been the victim of these acts.

To the best of our knowledge, this is the first study to examine the correlation of victimization to years of farming experience. As indicated in Table 4, years of experience was broken into three categories: less than 10 years, between 10 and 24 years, and 25 years or more. Of these three groups, those with 25 years or more experience in farming indicated higher levels of victimization. In fact, those in this category reported higher rates of victimization than the other two categories (less than 10 years and between 10 and 24 years) combined regardless of offense although only theft and poaching were found to be statistically significant. 
Table 4: Agricultural Victimization within the Past 12 Months

\begin{tabular}{lcccccc}
\hline Crimes & \multicolumn{7}{c}{ Years Farming } \\
\hline & & & & & Chi- \\
& All & $<10$ & $10-24$ & $>25$ & Missing & Square \\
\hline Theft & $33.4 \%$ & $3.0 \%$ & $5.2 \%$ & $16.3 \%$ & $8.9 \%$ & $9.346^{*}$ \\
Vandalism & $16.3 \%$ & $1.8 \%$ & $2.3 \%$ & $8.4 \%$ & $3.8 \%$ & 3.050 \\
Illegal Dumping & & & & & & \\
$\quad$ of Refuse & $30.1 \%$ & $3.4 \%$ & $5.8 \%$ & $15.7 \%$ & $5.2 \%$ & 0.439 \\
Trespass & $44.0 \%$ & $4.3 \%$ & $10.1 \%$ & $22.7 \%$ & $6.9 \%$ & 2.630 \\
Poaching & $27.5 \%$ & $2.2 \%$ & $6.3 \%$ & $13.9 \%$ & $5.2 \%$ & $9.157^{*}$ \\
\hline
\end{tabular}

${ }^{*}$ Chi-square statistic is significant at .05

According to participant comments, most of the instances of trespass were related to hunting and fishing activities although they rarely caught the perpetrator(s) in the act. Instead, evidence of hunting and fishing (i.e., carcasses, etc.) were the most common indicator provided to suggest that trespassing had occurred. In relation to theft, most participants indicated that they either had no way of proving the theft or had no way of specifying when the act occurred. Items stolen ranged from sheet metal, pecans, fuel, and livestock allegedly stolen by a livestock sale barn.

Prior studies have found that rural crimes frequently go unreported to the police (Weisheit and Donnermeyer 2000; Barclay et al. 2001; Mears et al. 2007). While the degree to which the offenses within the current study were reported to police varied, the overall finding was consistent with prior studies. Of the offenses, theft was reported to the police (58\%) more frequently while illegal dumping was least reported (21\%). These findings suggest that the degree to which these acts are perpetrated are relatively unknown and that there still exists a dark figure of crime in regards to agricultural offenses.

\section{Discussion}

The study was designed to provide at least an exploratory examination of the prevalence of crime on agricultural operations in the State of Georgia, and more specifically the correlation between victimization and farm size and years of experience in farming. The project revealed that larger farms were more frequently victims of agricultural offenses, which was consistent with the findings of prior studies examining farm crime (McCall 2003; Mears et al. 2007). These offenses were also found to be more often committed against individuals with many years of farming experience. While both findings contribute to our current knowledge of agricultural crime, the correlation between years of farming experience and victimization was unique to this project as it has not been previously examined by other researchers. 
The finding that larger farms and more experienced farmers are often the victims of agricultural crime demonstrates that these offenses are not randomly perpetrated. Instead, these offenses appear to be committed against individuals who are generally more established within the farming community in terms of longevity within the profession and the accumulation of property to advance their farm enterprise. The longer an individual stays within a specific occupation and the more vested that individual becomes in their career, as demonstrated through an increase in farming acreage, the more likely they are to accumulate various tools (i.e., machinery, etc.) necessary to more efficiently carry out their duties. These tools in farming are often very portable and easy targets of theft and vandalism (Barclay et al. 2001). As a result, these offenses appear to be financially motivated as the very commission of these acts impacts the overall productivity of farming operations and has a negative result on the underlying profitability of the enterprise.

Although the study is methodologically sound and the results do add to our understanding of agricultural crime, there are a few notable limitations that were encountered. The most obvious limitation was the low response rate. Ideally, criminological research seeks to have a survey response rate of 20 percent or greater. As already mentioned, the study response rate of 4.15 percent is in conformity to the normal response rate of similar electronic surveys distributed by the Georgia Farm Bureau to their membership (4-5\%). While significantly lower than the ideal for criminological research, it is unreasonable to believe the current survey would have had a higher response rate in comparison to similar surveys by Georgia Farm Bureau.

While Georgia Farm Bureau reportedly sent the electronic survey link to 10,000 Georgia Farm Bureau members with email addresses on file, there was no way of knowing whether all email addresses were current and actively being monitored/used by the members, or that they are actively involved in farmers, as many people join a state Farm Bureau for insurance discounts and other benefits. As a result, the response rate may have actually been higher. Similarly, if active, no information is known as to how often these email accounts are checked. In this event, it is likely that some of the email accounts may have been unmonitored during the time span of this study. It is also possible, given the age range of the participants, that other older farmers may not utilize technology, including the Internet as frequently as younger individuals do.

The topic of this study is also a sensitive issue that may create a certain amount of reluctance within potential subjects. Members of rural society are generally perceived to be suspicious and cautious with "strangers". Although the study had the support of Georgia Farm Bureau and was distributed to the prospective respondents by Georgia Farm Bureau, it is possible that some of the intended participants elected to not take part in this project due to not knowing the researchers and, thus, perceiving the researchers to be "strangers". 


\section{Conclusion}

Agricultural crime continues to be a frequently ignored subject of inquiry within criminological research although the commission of these type acts is of equal important to events perpetrated against businesses in more urban environments. This study, to the best of our knowledge, is the first project to examine farm crimes in Georgia. Based on the results, it is argued that these type offenses, when considering the specified time frame of the prior 12 months, do occur rather frequently. While this study does provide at least a cursory glimpse of the degree of victimization from these acts, there is a need for more research on these events as many questions remain unanswered. Although it was outside the scope of the current project, future research should focus on why these acts routinely go unreported to the police. An analysis of these reasons is necessary in order for the legal system to better serve those in agricultural settings while protecting them from becoming victims of these acts. Additionally, future studies should also examine the various measures used by farm operators to protect themselves and their agricultural property from victimization while also looking at farmers' perception of their own safety or the vulnerability of farm property to crime. Another suggestion for future research is for more in-depth studies using technologies, such as geographic information systems (GIS), to determine any potential "hotspots" of vulnerability to crime on farm operations.

All crime is traumatic to victims and negatively impactful for society, yet some criminal acts go unrecognized within the legal system and scientific discussions. A secondary aim of this project is to bring recognition to an overlooked population in rural society whose victimization is equally devastating in comparison to those in urban environments. The pursuit of justice comes in giving credence to the equality of these acts in different settings. For these victims, justice will only come through understanding the nature and prevalence of these acts, the factors that may motivate the perpetration of these events, and how to best respond these situations when they occur. In summation, justice cannot be fully achieved if agricultural crimes continue to be ignored within criminological studies. 


\section{References}

Anderson, K. M., and McCall, M. (2005). Farm Crime in Australia. Canberra, AU: Australian Institute of Criminology.

Barclay, E. M. (2001). A Review of Related Literature on Agricultural Crime. Institute for Rural Futures, University of New England, retrieved on $14^{\text {th }}$ December, 2015 from: www.criminologyresearchcouncil.gov.au/reports/barclay.pdf

Barclay, E., and Donnermeyer, J. F. (2011). Crime and security on agricultural operations. Security Journal, 24, 1-18, https://doi.org/10.1057/sj.2008.23

Barclay, E. M., Donnermeyer, J. F., Doyle, B. P., and Talary, D. (2001). Property Crime Victimisation and Crime Prevention on Farms. Report to the NSW Attorney General's Crime Prevention Division (Report No. 01.2). Armidale, New South Wales: Institute for Rural Futures, University of New England.

Bunei, E. K., Rono, J. K., and Chessa, S. R. (2013). Factors influencing farm crime in Kenya: Opinions and experiences of farmers. International Journal of Rural Criminology, 2(1), $75-100$.

Cleland, C. L. (1990). Crime and Vandalism on Farms in Tennessee. Report of the Agricultural Experiment Station, Institute of Agriculture. Knoxville, TN: University of Tennessee.

Cromartie, J. (2013, May 24). How is Rural America Changing? United States Department of Agriculture.

Deeds, J., Frese, W., Hitchner, M., and Solomon, M. (1992). Farm Crime in Mississippi. Report to the Mississippi Agricultural and Forestry Experiment Station. Mississippi State, MI: Mississippi State University. Bulletin 987.

DeKeseredy, W. S., Donnermeyer, J. F., Schwartz, M. D., Tunnell, K. D., and Hall, M. (2007). Thinking critically about rural gender relations: Toward a rural masculinity crisis/male peer support model of separation/divorce sexual assault. Critical Criminology, 15, 295 - 311, https://doi.org/10.1007/s10612-007-9038-0

DeKeseredy, W. S., Muzzatti, S. L., and Donnermeyer, J. F. (2013). Mad men in bib overalls: Media's horrification and pornification of rural culture. Critical Criminology, 22, 179197, https://doi.org/10.1007/s10612-013-9190-7 
Donnermeyer, J. F. (1987) Crime Against Farm Operations. Report of the National Rural Crime Prevention Center. Columbus, OH: Department of Agricultural Economics and Rural Sociology, The Ohio State University.

Donnermeyer, J. F. and Barclay, E. M. (2005). The Policing of farm crime. Police Practice and Justice Research, 6, 3-17, https://doi.org/10.1080/15614260500046913

Donnermeyer, J. F., Barclay, E., and Mears, D. P. (2011) Policing agricultural crime. In R. I. Mawby and R. Yarwood (eds.), Rural policing and policing the rural: A constable countryside? (pp. 193-204). Farnham, UK: Ashgate.

Donnermeyer, J. F., and DeKeseredy, W. S. (2014). Rural Criminology: New Directions in Critical Criminology. New York, NY: Routledge.

Donnermeyer, J. F., and Tunnell, K. (2007). In our own backyard: Methamphetamine manufacturing, trafficking, and abuse in rural America. Rural Realities, 2(2). Online at www.ruralsociology.org/wp-content/uploads/2012/03/Rural-Realities-2-2.pdf.

Dunkelberger, J. E., Clayton, J. M., Myrick, R. S., and Lyles, G. J. (1992). Crime and Alabama Farms: Victimization, Subjective Assessment, and Protective Action. Alabama Agricultural Experiment Station: Auburn University.

Farmer, F. L. and Voth, D. E. (1989). Ecological Characteristics of Farm Victimization in Arkansas. Report to the Arkansas Agricultural Experiment Station. Fayetteville, AK: University of Arkansas. Bulletin 917.

Georgia Department of Agriculture. (January 2012). Report on Agriculture Labor. Atlanta: Georgia Department of Agriculture.

Grant, J. (2008). Charting women's journeys: From addiction to recovery. Lanham, MD: Lexington.

Grant, J. (2012). Men and substance abuse: Narratives of addiction and recovery. Boulder, CO: First Forum Press.

Jobes, P. C., Barclay, E., Weinand, H., and Donnermeyer, J. F. (2004). A structural analysis of social disorganisation and crime in rural communities in Australia. Australian and New Zealand Journal of Criminology, 37, 114-140, https://doi.org/10.1375/acri.37.1.114 
Jones, J. (2008). Farm Crime on Anglesey: Local Partner's and Organisations. Views on the Issue. Aberystwyth, Wales: Aberystwyth University. Second report, January.

McCall, M. (2003). Results from the 2001-02 National Farm Crime Survey. Australian Institute of Criminology, Trends and Issues in Crime and Criminal Justice, No. 266.

Mears, D. P., Scott, M. L., and Bhati, A. S. (2007). Opportunity theory and agricultural crime victimization. Rural Sociology, 72, 151-184, https://doi.org/10.1526/003601107781170044

Peale, K. O. (1990). Crime and Vandalism on Farms in Kentucky. Frankfort: Kentucky State University. Community Research Service.

Swanson, C. R., and Territo, L. (1980) Agricultural crime: Its extent, prevention, and control. FBI Law Enforcement Bulletin, 49, 8-12.

Tunnell, K. D. (2004). Cultural constructions of the hillbilly heroin and crime problem. In J. Ferrell, K. Hayward, W. Morrison, and M. Presdee (Eds.), Cultural Criminology Unleashed (pp. 133-142). London: Glass House Press.

United States Census Bureau. (2010). 2010 Census Urban and Rural Classification and Urban Area Criteria. Retrieved from https://www.census.gov/geo/reference/ua/urban-rural 2010.html

United States Census Bureau. (2014). Florida Passes New York to Become the Nation's Third Most Populous State, Census Bureau Reports. Retrieved from http://www.census.gov/newsroom/press-releases/2014/cb14-232.html

United States Department of Agriculture Economic Research Service. (2015, May 14). Ag and Food Sectors and the Economy. Retrieved from http://www.ers.usda.gov/data products/agand-food-statistics-charting-the-essentials/ag-and-food-sectors-and-the economy.aspx

University of Georgia Extension Service. (n.d.). Agriculture. Retrieved from http://extension.uga.edu/agriculture/

Weisheit, R. A. (2008). Making methamphetamine. Southern Rural Sociology, 23, 78-107.

Weisheit, R. A. and Donnermeyer, J. F. (2000). Change and continuity in crime in rural America. In G. LaFree, J.F. Short, R.J. Bursik, Jr., and R.B. Taylor (Eds.), The Nature of Crime: Continuity and Change, 1 (pp. 309-358). Washington, D.C.: U.S. Department of Justice, Office of Justice Programs. 
International Journal of Rural Criminology, Volume 3, Issue 2 (June), 2017

Weisheit, R. A., Falcone, D. N., and Wells, L. E. (1999). Crime and Policing in Rural and Small Town America. $2^{\text {nd }}$ Ed. Prospect Heights, Illinois: Waveland Press. 